\title{
The Impact of Storm Tracks on Warm-Season Precipitation in the Midwest: Contrasting the 1988 Drought and 1993 Flood
}

\author{
Timothy Paul Eichler' ${ }^{1}$ and Zaitao Pan ${ }^{2}$ \\ ${ }^{1}$ School of Education, Saint Louis University, St. Louis, MO 63108, USA \\ ${ }^{2}$ Department of Earth and Atmospheric Sciences, Saint Louis University, St. Louis, MO 63108, USA \\ Correspondence should be addressed to Timothy Paul Eichler; teichler@slu.edu
}

Received 13 February 2015; Revised 18 May 2015; Accepted 26 May 2015

Academic Editor: Igor I. Mokhov

Copyright ( 2016 T. P. Eichler and Z. Pan. This is an open access article distributed under the Creative Commons Attribution License, which permits unrestricted use, distribution, and reproduction in any medium, provided the original work is properly cited.

\begin{abstract}
To assess the role of cyclone tracks in contributing to floods and droughts, we highlight the role of midlatitude cyclones played in the 1988 drought and the 1993 flood. Our results demonstrate that the 1988 drought featured a poleward-displaced cyclone track with a reduced role for cyclone-induced precipitation, especially in the spring of 1988. The 1993 flood featured a cyclone track from Mexico northeast to Missouri in the spring, while the summer featured two cyclone tracks: one in the southwestern US and the other across Canada linked to the right-entrance and left-exit regions of a strong $200 \mathrm{hPa}$ Jetstream across the upper Midwest. Enhanced $850 \mathrm{hPa}$ inflow from the Caribbean northeast to the Midwest with high precipitable water values occurred in conjunction with the right entrance portion of the $200 \mathrm{hPa}$ Jetstream. Linking storm tracks and the $200 \mathrm{hPa}$ Jetstream to a storm-rain index for the Midwest showed that these extreme events conformed to features of the general circulation normally associated with wet/dry episodes in the warm half of the year. Although El Niño did not play a role in the 1993 flood, the 1988 drought was associated with a poleward displacement of cyclone tracks in response to La Niña.
\end{abstract}

\section{Introduction}

Droughts and floods are major weather-induced disasters causing tens of billions of dollars in economical loss [1]. The drought of 1988 and the flood of 1993 in the Mississippi River Basin are major extremes in recent decades. The extent of these events is shown in Figure 1. Figure 1(a) shows the extent of the 1988 drought on June 15 as reported in Changnon [2]. Severe to extreme drought covers a large portion of the Mississippi River Basin. The 1988 drought and associated heat waves across a large portion of the US resulted in $\$ 20$ $\$ 40$ billion dollar economic loss and caused hundreds of deaths. In contrast, Figure 1(b) is taken from Wahl et al. [3] and shows areas of the Mississippi River Basin where repeat thunderstorm events occurred. The record 1993 flood (named "Great Flood") was the wettest summer on record in many parts of the Midwest and inflicted a \$21-\$34 billon dollar loss and resulted in 48 casualties [1]. The drought of 1988 and the flood of 1993 represent by-products of extremes in the North American general circulation. Both of these events developed in the spring of their respective years and continued through the summer.

The drought of 1988 was characterized by an intensification of the $200 \mathrm{hPa}$ climatological April-June (AMJ) Northern Hemisphere circulation featuring anticyclonic centers over the central Pacific and the northern half of the United States, with cyclonic centers over the Gulf of Alaska and the southeastern United States [4-6]. The intensification of the North American ridge resulted in a poleward-displaced Jetstream and, hence, a northward displaced cyclone track. In contrast, the flood of 1993 was characterized by a western US trough and eastern US ridge during later spring and summer [6-8]. Specifically, Bell and Janowiak [8] noted that this pattern became established in June 1993, with a western ridge dominant in the previous months. The resultant pattern featured a southward displacement of the Jetstream implying a southward-displaced cyclone track [9]. The consequences of this pattern were increased low-level jet (LLJ) transporting moisture into the Midwest. This, coupled with the flood region being in the right-entrance quadrant of an anomalous 


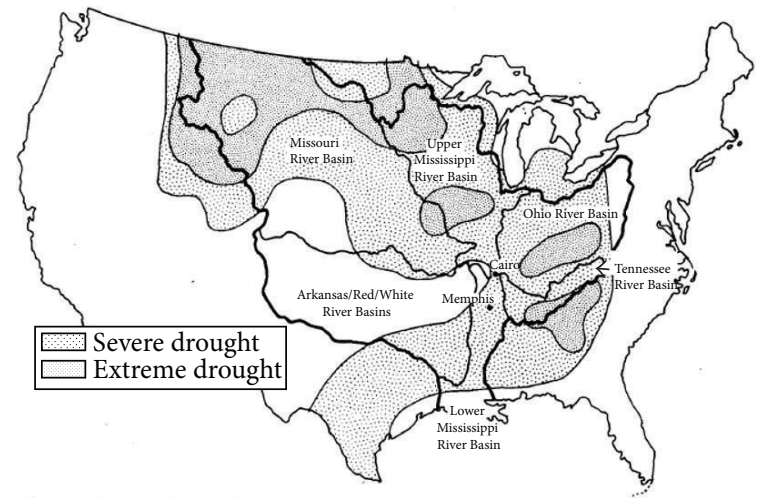

The areas of severe and extreme drought in the Mississippi River Basin on 15 June 1988 (based on Palmer drought severity index).

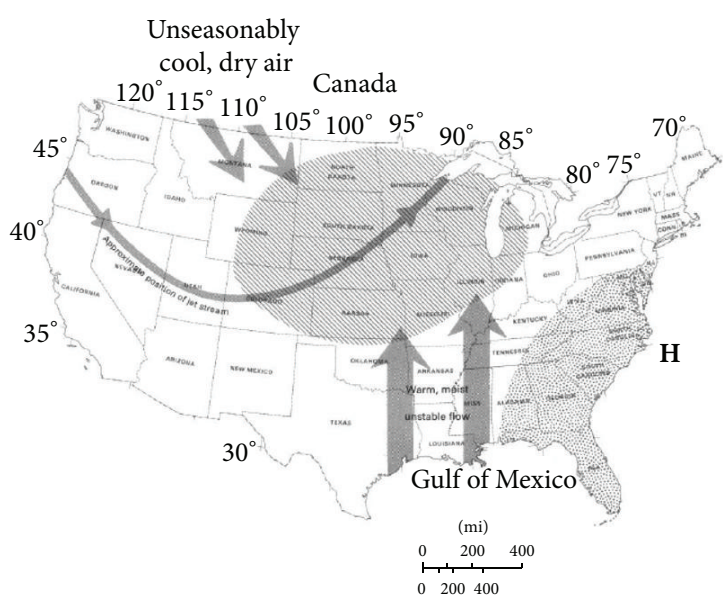

Explanation

$(\mathrm{km})$

Convergence zone; recurrent thunderstorm systems

$\square$ Little rainfall; oppressive heat and humidity

H High atmospheric pressure area

Dominant weather patterns over the United States for June through July 1993 (from national weather services, 1993).

(a)

(b)

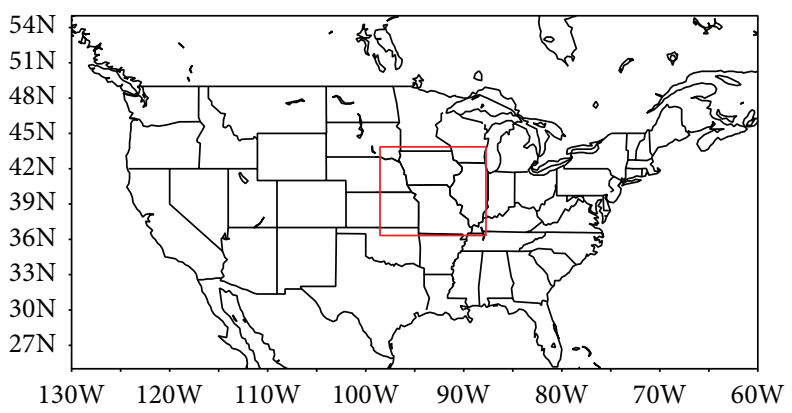

(c)

Figure 1: (a) Schematic of 1988 drought from Changnon [2]. (b) Schematic of 1993 flood from Wahl et al. [3]. (c) Area used to tabulate storm-rainfall index (red rectangle).

strong $200 \mathrm{hPa}$ Jetstream downstream of the western US trough, resulted in an increased frequency of Mesoscale Convective Complexes (MCCs) [8]. On a subsynoptic scale, Weaver et al. [10] determined that southern plains lowlevel jet anomalies resulted in increased moisture flux and precipitation anomalies in the northern plains.

Causes of the 1988 drought and 1993 flood are rather complex. For example, Namias [11] stated that local impacts of dry soil anomalies from the spring resulted in a persistent pattern favoring drought. In addition, Namias [11] stated that La Niña was not likely a factor since seasonal predictions for the spring/summer made in March pointed towards drier than normal conditions prior to the onset of La Niña. However, Trenberth and Branstator [12] emphasized that the large-scale SST pattern in the North Pacific (not just La Niña) may have contributed significantly to the 1988 drought via a shift in the Intertropical Convergence Zone (ITCZ) resulting in subtropical North Pacific heating anomalies. While Seager and Hoerling [13] state that sea-surface temperatures in the Pacific via ENSO and in the Atlantic via persistence play a role in circulation anomalies leading to drought, they also acknowledge the role of internal variability (i.e., weather). For example, Seager and Hoerling [13] describe how the SST conditions in 1973-1975 favored drought across the southern US although this did not occur. In contrast, Hoerling and Kumar [14] used a multimodel GCM ensemble to link the 1998-2002 US drought to La Niña conditions. They also found above normal precipitation across Canada. Hoerling and Kumar [14] demonstrated that the dry (wet) conditions across the US (Canada) were caused by a poleward shift in the Jetstream, with above normal $200 \mathrm{hPa}$ heights dominating the midlatitudes.

For the 1993 flood, antecedent wet soil moisture anomalies likely played a role in exacerbating the event [15]. For example, Kunkel et al. 1994 discussed that conditions were wet from July 1992 to the summer of 1993 with seven of eleven months preceding the flood having above normal precipitation. In addition, Kunkel et al. [7] noted that AMJ 1993 was anomalously wet in the Midwest resulting in saturated soil; hence, additional rainfall went into run-off into the 
Mississippi as opposed to being absorbed locally. Although not completely responsible, Trenberth and Guillemot [9] described how a mature El Niño in the spring of 1993 and its associated anomalous convection resulted in an alteration of the large-scale circulation and hence a rearrangement of the planetary waves, jetstream, and cyclone track via an atmospheric response due to heating anomalies. Weaver et al. [10] also implicated the North Atlantic Oscillation (NAO) as a contributor to the circulation pattern responsible for the 1993 flood, with $25 \%$ of the precipitation and Great Plains lowlevel jet anomalies being produced by ENSO and the NAO. On the subsynoptic scale, Pan et al. [16] found that a quasistationary cyclonic circulation over the central US supported widespread heavy rainfall events.

While the above studies do an excellent job in describing the synoptic features and large-scale causes of the 1993 flood and 1988 drought, cyclone tracks are mentioned only as a feature of the Jetstream or as defined as an upper-troposphere cyclone track (e.g., [9]). However, it is the surface-based cyclone tracks which have a direct impact on precipitation anomalies. Therefore, this study emphasizes the role that surface-based cyclone tracks play in the flood of 1993 and the drought of 1988. To show the evolution of cyclone tracks, we display cyclone tracks from October-December (OND) 1992 through July-August (JAS) 1993. We also include link cyclone tracks in diagnostics of the general circulation and associated precipitation from CFS Reanalysis data (CFSR), which has a $0.5^{\circ} \times 0.5^{\circ}$ (lat/lon) horizontal grid [17]. Section 2 describes the datasets/methodology of this paper. Section 3.1 discusses results linked to aspects of the general circulation for the 1988 drought and 1993 flood, while Section 3.2 verifies that the results from Section 3.1 were related to the overall behavior of storm tracks and the general circulation via a storm-rainfall index. A brief discussion of the possible role of ENSO is also given. Finally, Section 4 will give our conclusions.

\section{Methodology/Datasets}

Cyclone track software used in our study generates cyclones by locating a local minimum in sea-level pressure (SLP) in a grid-box relative to surrounding grid boxes as described in Serreze [18] and Carse et al. [19]. This method is well established in the storm track literature and has been included in the Intercomparison of Mid-Latitude Storm Diagnostics (IMLAST) project (Neu et al. [20]). We utilize a one $\mathrm{hPa}$ threshold for finding cyclones and a maximum propagation of $800 \mathrm{~km}$. between time steps as described in Eichler and Higgins [21]. Seasonal cyclone track frequency is computed by accumulating cyclones in a $5^{\circ} \times 5^{\circ}$ (lat/lon) cyclonecentered box as first used by Eichler and Higgins [21].

Input for the cyclone tracks program is supplied by 6hourly SLP from the CFSR dataset. For the 1988 drought, we generate seasonal cyclone tracks from OND 1987 through JAS 1988, while, for the 1993 flood, cyclone tracks are generated from OND 1992 through JAS 1993. To assess the role of cyclone tracks in the synoptic environment, we also generate seasonal means (same time periods as the cyclone tracks) for $200 \mathrm{hPa}$ wind, $850 \mathrm{hPa}$ wind, $200 \mathrm{hPa}$ height, $500 \mathrm{hPa}$ height, and precipitation from monthly CFSR data. To determine the linkage of cyclones with precipitation, we compute cyclonerelated precipitation by computing precipitation for each cyclone in a $9^{\circ} \times 9^{\circ}$ (lat/lon) cyclone-centered box. This method was used by Eichler and Higgins [21] to assess cyclone-related precipitation climatology relative to total precipitation climatology. The $9^{\circ} \times 9^{\circ}$ (lat/lon) cyclone-centered box was found to yield the best results as it captures most of the synoptic-scale precipitation associated with an individual cyclone.

To explore the relationship between storm-related rainfall, storm frequency, and aspects of the general circulation, we constructed a seasonal storm-rainfall index by summing monthly CFSR rainfall data for an area affected significantly by both the 1988 drought and 1993 flood (Figure 1(c)). Inspection of Figures 1(a) and 1(b) shows the area chosen in Figure 1(c) as an appropriate compromise representing both of these extreme events.

To evaluate the role that ENSO may play in cyclone tracks, a correlation of cyclone track frequency with the ENSO Intensity Scale (EIS) is shown for JAS. The EIS index was developed by Kousky and Higgins [22] and is a five-class intensity scale that is calculated by doubling the oceanic Niño index (ONI), defined as the 3-month running mean of SST anomalies for the Niño-3.4 region.

Finally, we present several of our results as 1993 differences relative to 1988 to emphasize the opposing circulation patterns of these two extreme years. We also correlate our rainfall index with storm track frequency and $200 \mathrm{hPa}$ winds to demonstrate that these extreme events agree well with overall relationships linking storm tracks with the general circulation.

\section{Results}

3.1. Circulation Patterns Associated with the 1988 Drought and 1993 Flood. The antecedent and concurrent seasonal $500 \mathrm{hPa}$ height patterns and anomalies derived from monthly CFSR data for the 1988 drought and 1993 flood are shown in Figures 2(a) and 2(b), respectively. The 1988 drought was marked by a persistent pattern consisting of an anomalously strong $500 \mathrm{hPa}$ trough in the Aleutians, an anomalously strong western ridge US, and an anomalously strong downstream trough over the eastern US from OND87 through AMJ88 (Figure 2(a)). The pattern is particularly amplified during the peak of the drought during AMJ88, with the western US ridge shifted slightly east to the US Great Plains. The pattern we see is similar to what is described by Liu et al. [6] as an amplification of the climatological Aleutian low/western US ridge/eastern US ridge. Furthermore, the pattern is marked by persistence to at least the previous fall. By JAS 88 , the pattern breaks down as evidenced by near normal $500 \mathrm{hPa}$ heights across the Midwest (Figure 2(a)). However, this period is climatologically drier in the Midwest relative to spring, so AMJ dry conditions would be maintained in the summer. The existence of the $588 \mathrm{DM}$ line closed ridge over the southern US during JAS88 would preclude persistent inflow from the Gulf of Mexico.

In contrast, the $500 \mathrm{hPa}$ seasonal height pattern for the antecedent (AMJ) and concurrent (JAS) 1993 flood period 
OND87

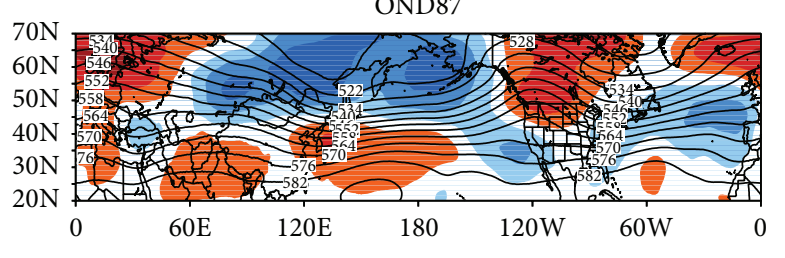

JFM88

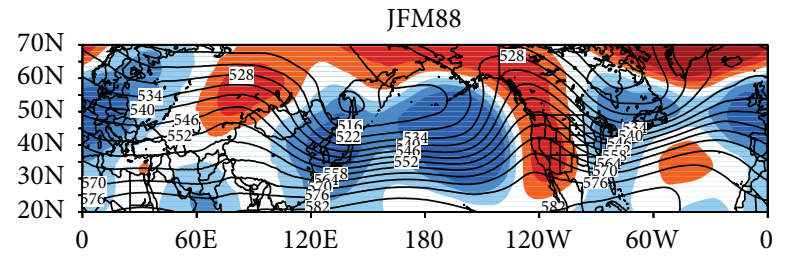

AMJ88

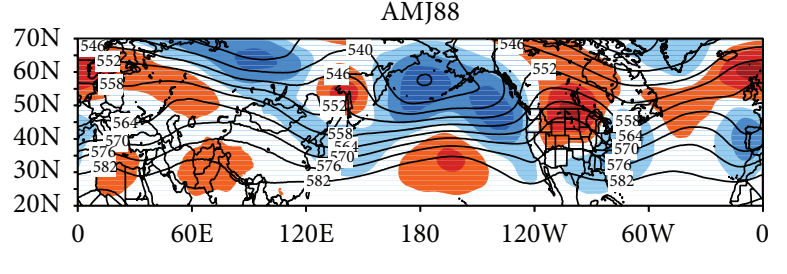

JAS88

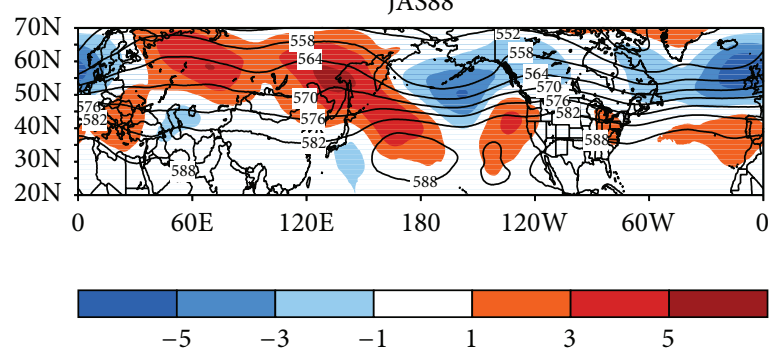

(a)

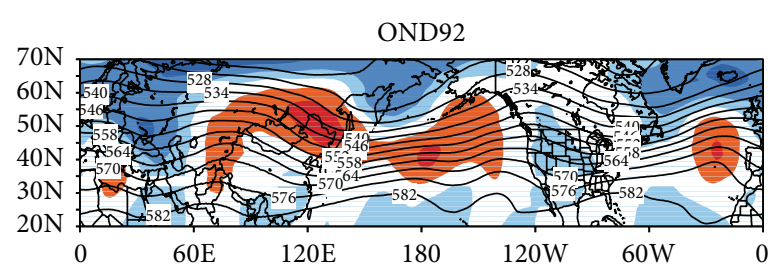

JFM93

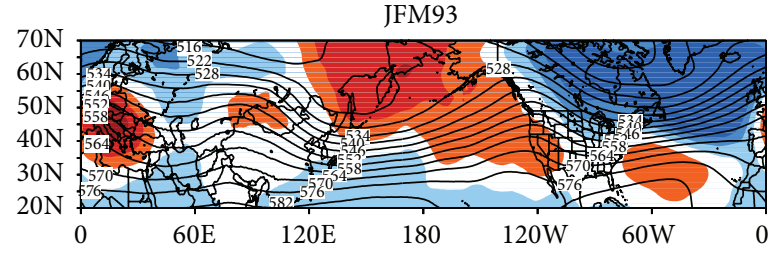

AMJ93
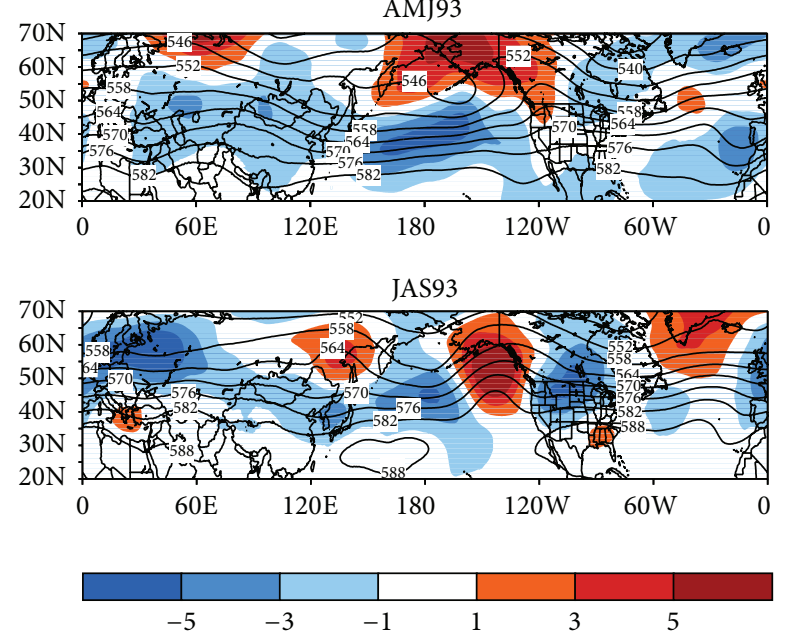

(b)

FIGURE 2: Seasonal $500 \mathrm{hPa}$ heights and departures from normal (decameters) from CFSR data for (a) OND87 through JAS88 and (b) OND92 through JAS93. Seasonal normal taken relative to 1979-2009.

is not as persistent as the 1988 drought. On the one hand, a persistent difference from the 1988 drought is the existence of above normal $500 \mathrm{hPa}$ heights in the Aleutians from OND92 through JAS93 as opposed to below normal $500 \mathrm{hPa}$ heights in the same region for the 1988 drought (cf. Figures 2(a) and 2(b)). The former would favor downstream troughing over the western US, while the latter would favor downstream ridging over the western US. Variability in the pattern during 1993 comes from the extent of the positive $500 \mathrm{hPa}$ height anomalies in the North Pacific, which extended into the eastern Pacific during OND92, with lower than normal heights across the western half of the US (Figure 2(b)). However, the positive height anomalies extend eastward the western US during JFM93, with the formation of a $500 \mathrm{hPa}$ ridge along the west coast (Figure 2(b)). By AMJ93, a split flow configuration becomes established with a $500 \mathrm{hPa}$ ridge persisting across western Canada and weak troughing developing over California (Figure 2(b)). Although the $500 \mathrm{hPa}$ height demarcating the subtropical ridge develops across the southern US in JAS93, it is suppressed south of the normal with below normal $500 \mathrm{hPa}$ heights dominating across the northern half of the US. The transition from a winter/early spring western US ridge to below normal late spring/summer $500 \mathrm{hPa}$ heights is consistent with the transition described by Bell and Janowiak [8]. The JAS93 $500 \mathrm{hPa}$ pattern also suggests a southward displaced cyclone track discussed by Trenberth and Guillemot [9]. The concurrent above normal $500 \mathrm{hPa}$ heights across the southeastern US during JAS93 would also support fronts stalling frequently across the Mississippi Valley as discussed by Kunkel et al. [7].

The precipitation anomalies derived from monthly CFSR data associated with the antecedent and concurrent 1988 drought are shown in Figure 3(a). During OND87, drier than normal conditions predominate over the southeastern US. By JFM88 this area persists and shifts slightly northwestward the lower Mississippi Valley (Figure 3(a)). These anomalies are consistent with $500 \mathrm{hPa}$ northwest flow between the western US ridge and the downstream eastern US trough (refer to Figure 2(a)). The expansion of the dry conditions across the central US during AMJ88 (Figure 3(a)) is in response to the overall amplification and eastward shift of the western US $500 \mathrm{hPa}$ ridge (refer to Figure 2(a)). By JAS88, the pattern dissipates, with generally normal to slightly dry conditions across the upper Midwest and with wetter than normal 

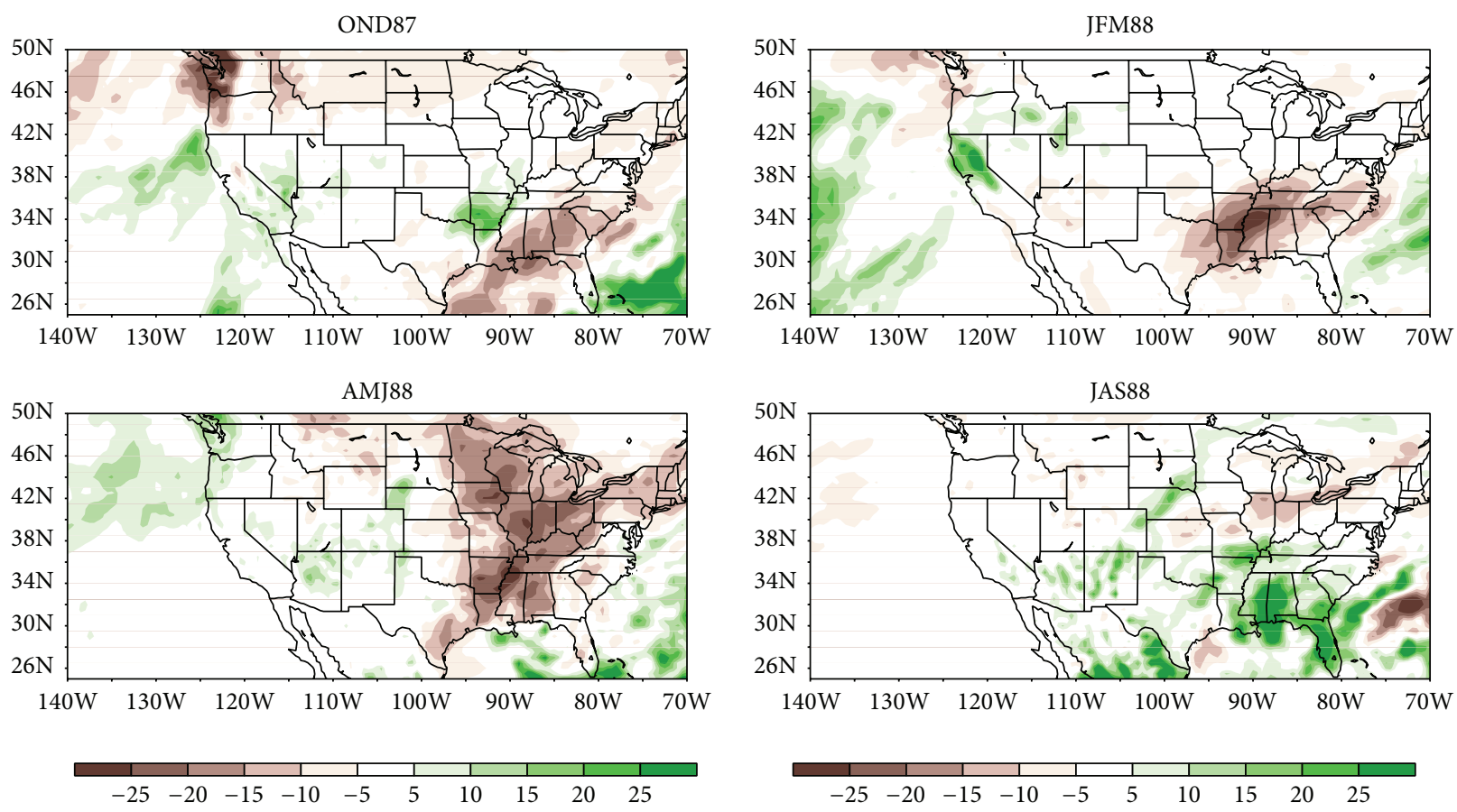

(a)
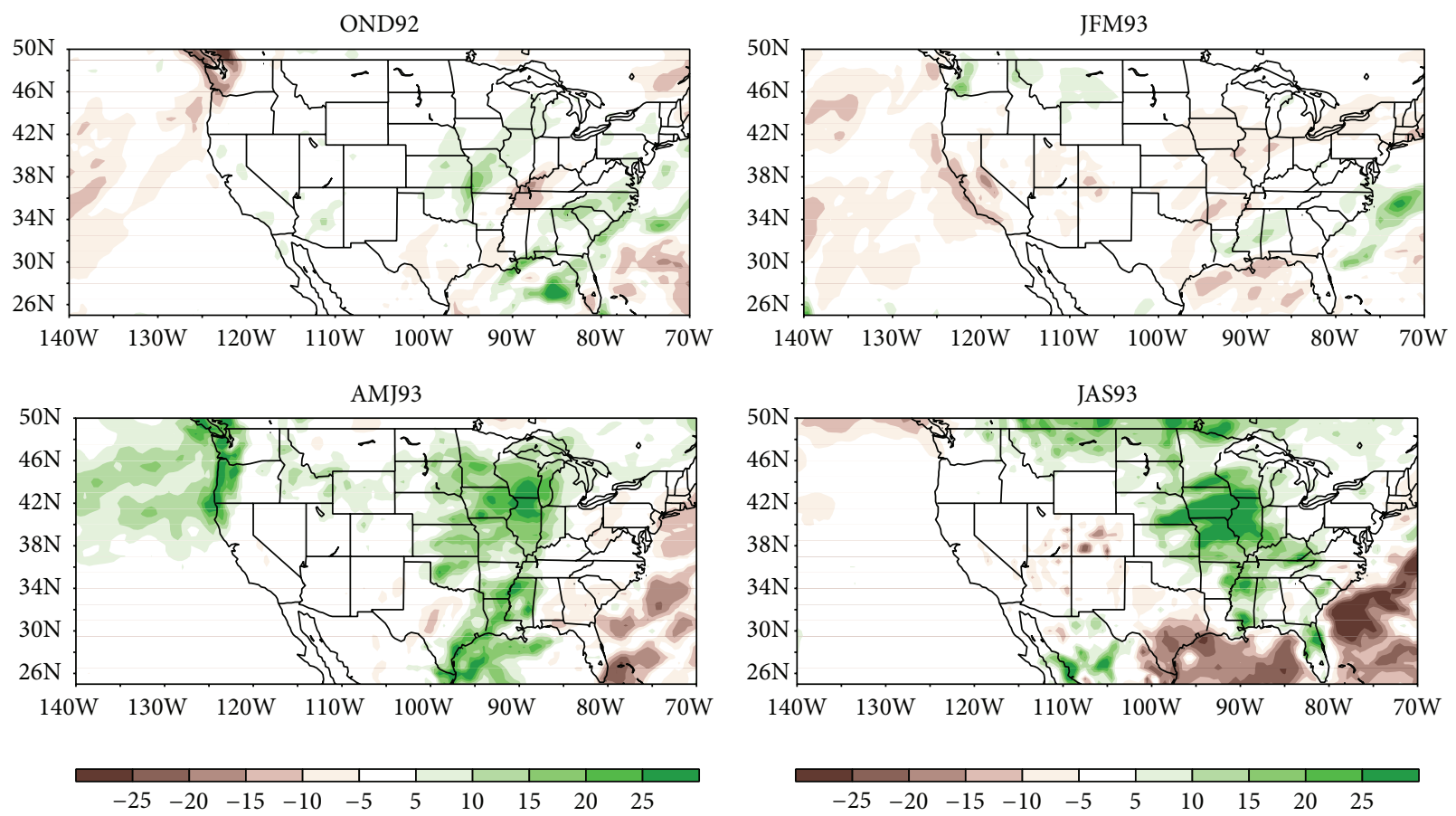

(b)

FIgURE 3: Seasonal precipitation departures from normal $(\mathrm{mm}$ ) from CFSR data for (a) OND87 through JAS88 and (b) OND92 through JAS93. Seasonal normal taken relative to 1979-2009.

conditions from the Gulf Coast northward to southern MO. Despite the return to near normal/slightly below normal precipitation across the major growing areas of the US in JAS88, the JAS rainfall climatology is less than the spring, so crops suffered from an abnormally dry spring transitioning to a near normal (dry) summer.
For the 1993 flood, a small region of wetter conditions is noted across Missouri during OND92 (Figure 3(b)). By JFM93, conditions are actually slightly drier than normal across the Mississippi Valley Basin; this is linked to the appearance of the $500 \mathrm{hPa}$ west coast ridge at the same time (refer to Figure 2(b)). This ridge favors (1) colder than 


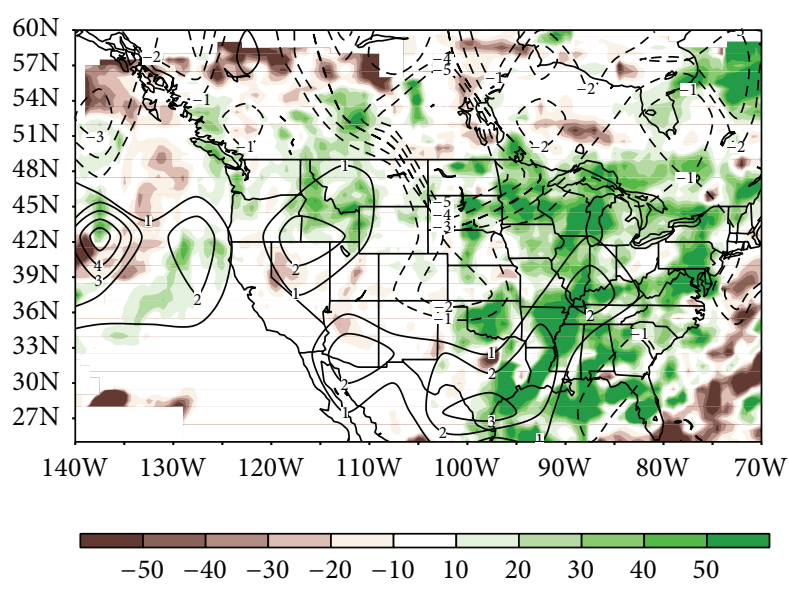

(a)

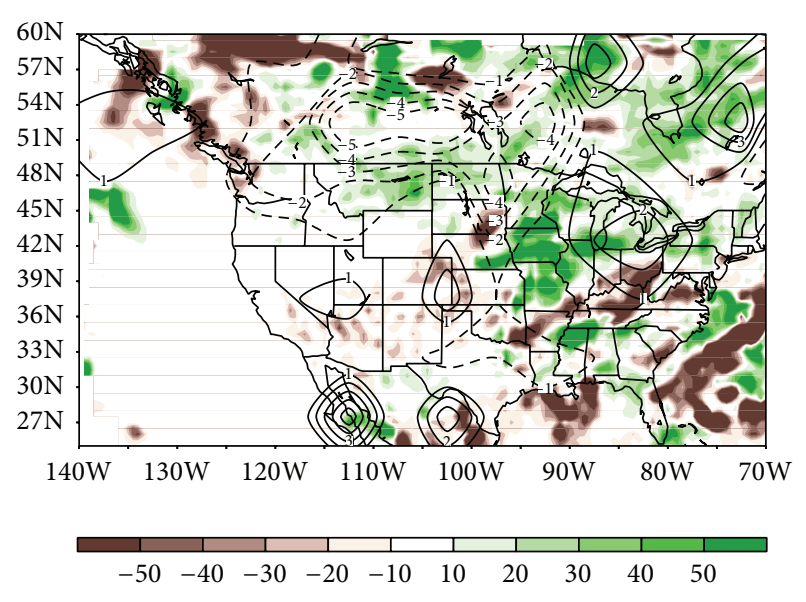

(b)

FIGURE 4: Cyclone frequency difference between 1993 and 1988 (contour) and cyclone-induced precipitation difference for 1993 minus 1988 (shaded in $\mathrm{mm}$ ) for (a) AMJ and (b) JAS. Data from CFSR.

normal conditions in the Midwest and (2) an increase in snowfall since the ridge would be sufficiently to the west to allow for an increase in cyclones. For example, St. Louis received 30 inches of snow for the winter of 1992/93, which is 11 inches above normal. So, despite slightly drier than normal conditions in JFM93, persistent snow cover would preclude the development of anomalously dry soil. By AMJ93, heavier than normal rainfall predominates across much of the Mississippi Valley (Figure 3(b)), which is exacerbated by snowmelt in the northern part of the basin. This is likely due to the replacement of the western US ridge with a mean trough, which would encourage a Pacific cyclone track entraining subtropical moisture. By JAS93, extremely wet conditions are seen across much of the Midwest, which is due to a southward displaced cyclone track (to be shown later), with frontal systems stalling in this region due to blocking from above normal $500 \mathrm{hPa}$ heights in the southeast (see Figure 2(b)).

3.2. Role of Cyclones in Midwestern Drought/Flood. To assess the role of midlatitude cyclone tracks in contribution to the 1993 flood and 1988 drought, we tabulate precipitation within a $9^{\circ} \times 9^{\circ}$ (lat/lon) box, with the cyclone at the center. As discussed by Eichler and Higgins [21], a $9^{\circ} \times$ $9^{\circ}$ (lat/lon) box is an appropriate size to capture much of the precipitation linked to cyclones. To emphasize the differences in cyclone tracks/impacts, we difference the 1993 flood cyclone track frequency/precipitation from the 1988 cyclone track frequency/precipitation for AMJ and JAS, respectively (Figure 4). For AMJ, a distinct southern cyclone track is observed in 1993 from the southwestern US eastward the Texas Gulf Coast and then northeastward the Ohio Valley (Figure 4(a)). This track is associated with heavy rainfall (relative to 1988) from Texas northeast to the Great Lakes. The southwestern US cyclone track is supported by upstream $500 \mathrm{hPa}$ troughing over southern California (refer to Figure 2(b)). In contrast, the 1988, cyclone track is displaced poleward relative to 1993 over the northern plains/southern Canada, supporting drier conditions across the major US farm belt and wetter conditions (brown areas in Figure 4(a)) across southern Canada. This pattern is supported by anomalously strong ridging across the US Great Plains in AMJ88 (refer to Figure 2(a)).

For JAS, the 1993/1988 differences are more zonally oriented. For example, a discontinuous cyclone track is noted in 1993 from the southern Rockies to the eastern Great Lakes, while the 1988 cyclone track is poleward in a zonal band from Washington State east-northeastward eastern Canada (Figure 4(b)). As will be discussed below, the discontinuity of the cyclone track may be related to the southwestern/northeastern portions of the cyclone track being under the right-entrance/left-exit portions of an anomalously strong $200 \mathrm{hPa}$ wind maximum, respectively, over the upper Midwest, which is an optimal location for cyclogenesis. Excessive rainfall associated with cyclone tracks is also seen in 1993 relative to 1988 across much of the Midwest eastward Michigan (Figure 4(b)).

The rainfall patterns associated with cyclone tracks in AMJ93 and JAS93 are the result of two different $200 \mathrm{hPa}$ wind patterns. For AMJ93, the cyclone track across Mexico to the Texas Gulf Coast and northeast to Missouri has its origins poleward of a strong subtropical wind maximum (Figure 5(a)). For Jas93, the cyclone track/rainfall pattern is tied to strong $200 \mathrm{hPa}$ winds situated over the upper Midwest (Figure 5(b)).

Figure 6(a) links cyclone tracks/low-level inflow to $200 \mathrm{hPa}$ winds for JAS93. Two areas of cyclones are noted: a weaker one over the right-entrance portion of the $200 \mathrm{hPa}$ maximum winds and the other over the left-exit portion of the $200 \mathrm{hPa}$ maximum winds. What is remarkable about this result is how persistent the pattern was over a whole season. Low-level $850 \mathrm{hPa}$ inflow from the Caribbean Sea westward the Texas Gulf Coast and then northeastward the Midwest is also notable and is consistent with a direct transverse circulation in response to the right-entrance region of the $200 \mathrm{hPa}$ wind maximum. 

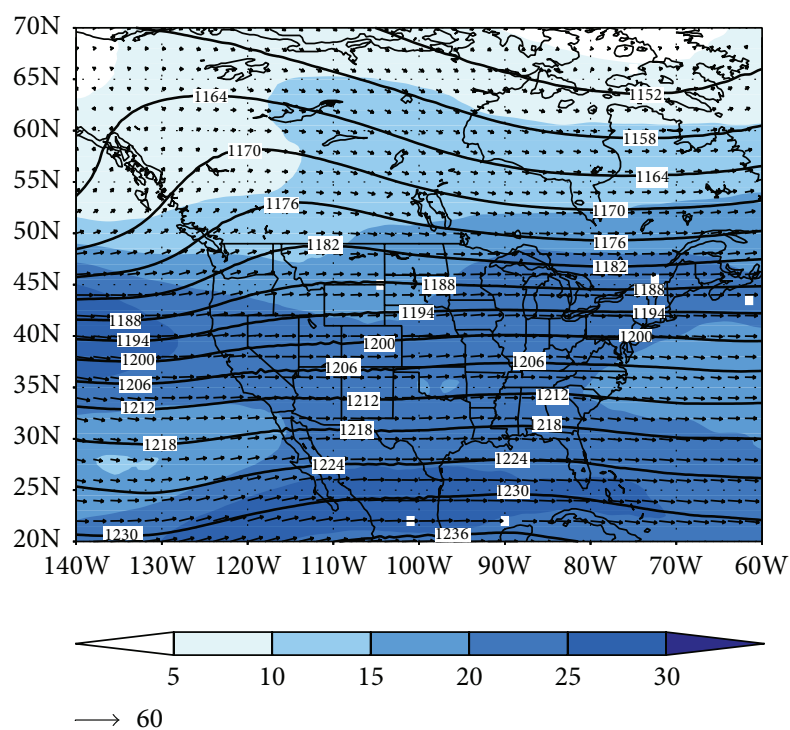

(a)
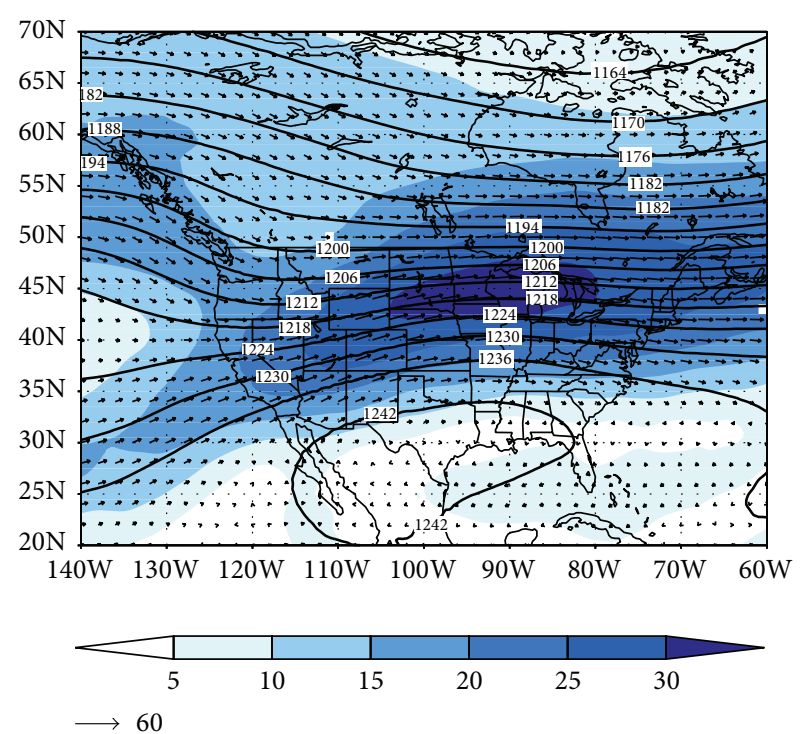

(b)

FIGURE 5: $200 \mathrm{hPa}$ height (contour, decameters) and wind (contour and vector m/sec) for (a) AMJ93 and (b) JAS93. Data from CFSR.

For JAS1988, the contribution of the $200 \mathrm{hPa}$ Jetstream to cyclone tracks is not clear. For example, a $200 \mathrm{hPa}$ wind maximum is noted displaced northeastward relative to 1993 across eastern Canada (Figure 6(b)). However, a maximum in cyclone frequency seen west of this $200 \mathrm{hPa}$ jet maximum across the far-northern US Great Plains/southern Canada does not appear to be associated with any particularly jet quadrant. It is quite possible that this cyclone maxima is linked to midlevel $(500 \mathrm{hPa})$ forcing associated with diffluence and subnormal $500 \mathrm{hPa}$ heights downstream of an anomalously strong $500 \mathrm{hPa}$ trough over the Gulf of Alaska in JAS88 (refer to Figure 2(a)). To compare the upper-level dynamics $/ 850 \mathrm{hPa}$ inflow related to cyclone tracks between JAS93 and JAS88, we generated their difference (Figure 6(c)). The outstanding features of Figure 6(c) (1993 relative to 1988) include (1) stronger $200 \mathrm{hPa}$ winds from the Rockies across the upper Midwest, (2) enhanced cyclone frequency located in the right-entrance/left-exit regions of this $200 \mathrm{hPa}$ wind maximum, and (3) stronger $850 \mathrm{hPa}$ inflow from the Gulf of Mexico. For 1988 relative to 1993, an increase in cyclone frequency is also seen in the northern US/southern Canada.

An interesting question is if the differences we see between the extreme flood/drought cases are the result of commonly-linked features of the general circulation or are isolated, unique events. Figure 7 shows the time series for the storm-rainfall index for AMJ and JAS (Figures 7(a) and 7(b)). The 1988 drought shows up well for AMJ (circled in Figure 7(a)), while the 1993 flood shows up well for JAS (circled in Figure 7(b)).

To see how the rainfall index is linked to storm tracks, we correlated the storm-rain index with storm track frequency for AMJ and JAS (Figures 8(a) and 8(b), resp.). Since the JAS storm tracks are climatologically shifted poleward, we focus on an area further north relative to AMJ. In Figure 8(a), we see significant, positive correlations in two areas: one over west Texas and Mexico and the other over the Midwest. This result implies an active (inactive) storm track from the southwestern US northeastward the Midwest producing an excess (deficit) of rainfall. Note that the discontinuity between the two areas is likely due to gridding of the storm tracks. When comparing Figure 8(a) to Figure 4(a), notice the agreement of the overall relationship of storm tracks to the differences between the 1993 and 1988 extreme events. Figure 8(b) shows a dipole structure with significant negative correlations across south-central Canada and significant positive correlations across southeastern Canada. When compared to Figure 6(c), the 1993/1988 JAS storm track differences show a strong resemblance to our findings in Figure 8(b) suggesting that variations in the $200 \mathrm{hPa}$ wind may play a major role in modulating JAS rainfall via moisture transport associated with secondary circulations linked to the jet. To explore this further, we correlated the JAS storm-rain index with the JAS $200 \mathrm{hPa}$ zonal wind (Figure 9). A large, zonally oriented area of significant positive correlation stretches from California east-northeastward the Great Lakes. Figure 9 supports our paradigm of a stronger (weaker) $200 \mathrm{hPa}$ speed max across the northern US producing more (less) storms in the rightentrance/left-exit regions of the jet, with strengthened (weakened) inflow from the Gulf of Mexico resulting in wetter (drier) conditions in JAS for our region of study.

The impact of stronger $850 \mathrm{hPa}$ inflow in 1993 relative to 1988 can be further illustrated by comparing precipitable water anomalies between 1988 and 1993 (Figure 10). For AMJ 1988, very low precipitable water in the Midwest (Figure 10(a)) is followed by near normal to slightly below normal precipitable water anomalies in JAS88 (Figure 10(b)). As discussed previously, the summer is climatologically drier than the spring in the Midwest, so very dry conditions in AMJ88 were a trigger for the 1988 drought. In contrast, for 1993, slightly higher than normal precipitable water in 

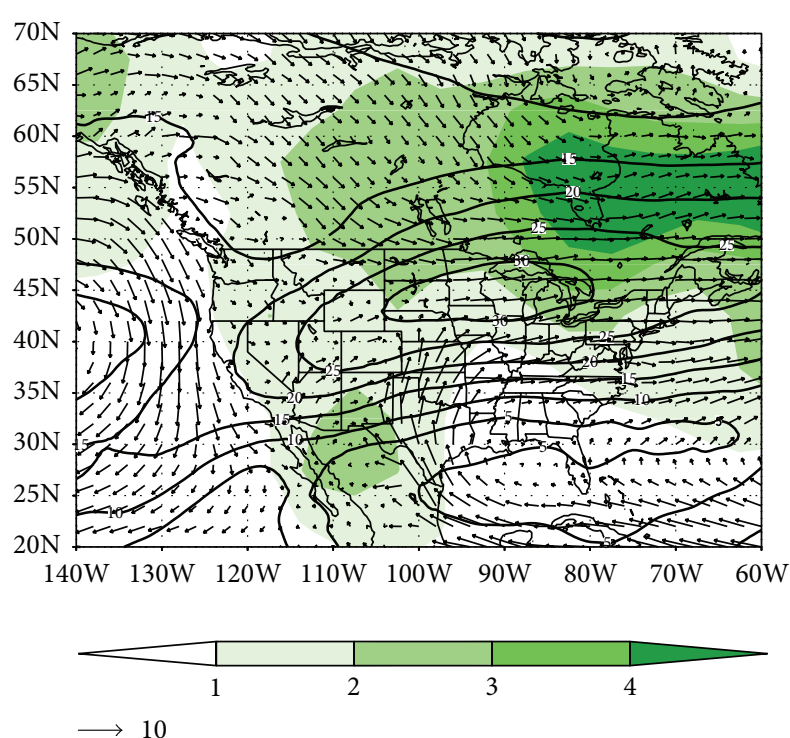

(a)
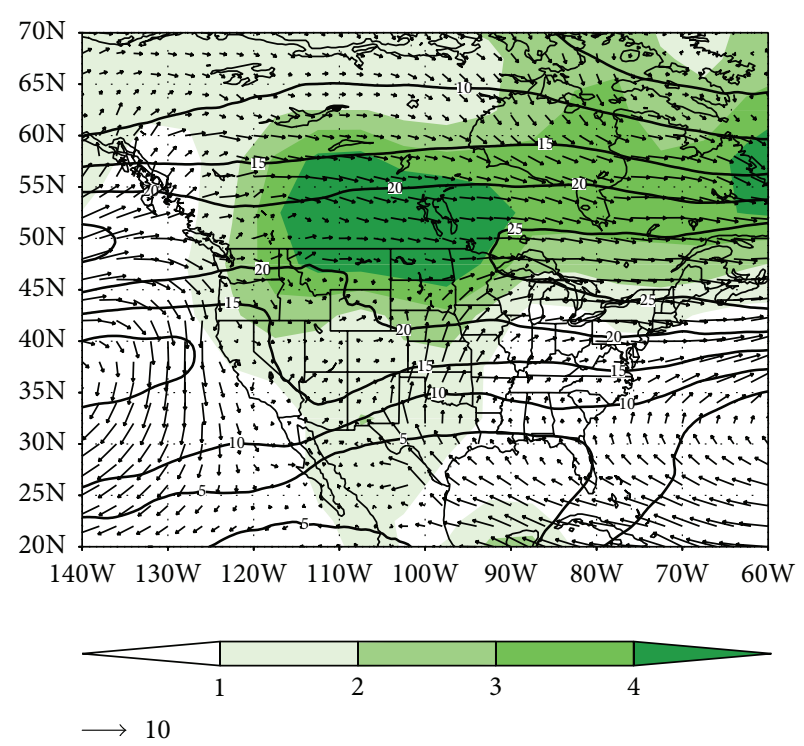

(b)
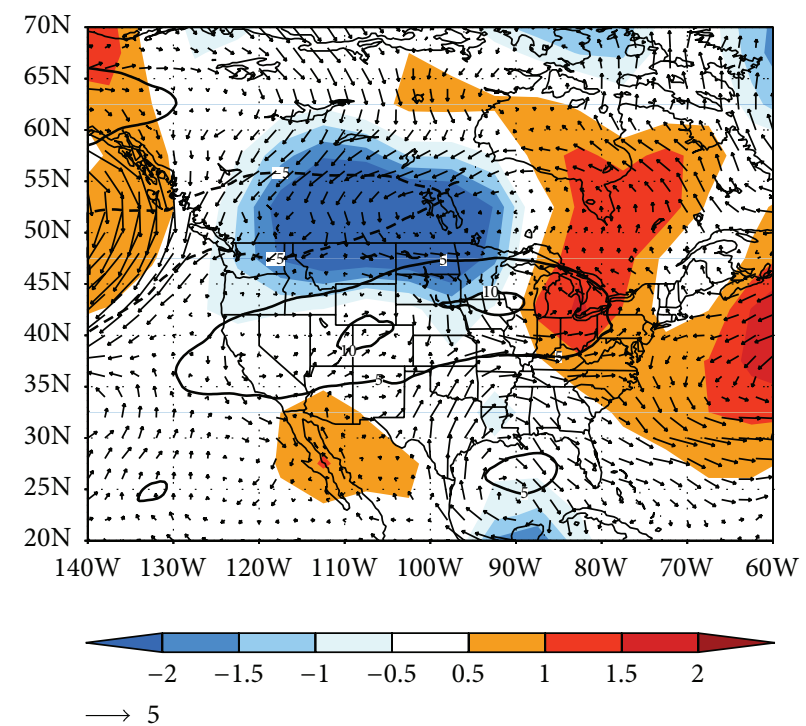

(c)

Figure 6: $200 \mathrm{hPa}$ wind (contour, m/sec), cyclone frequency (shaded), and $850 \mathrm{hPa}$ wind (vector, m/sec) for (a) JAS93, (b) JAS88, and (c) JAS93 minus JAS88. Data from CFSR.

the Midwest in AMJ93 (Figure 10(c)) was followed by much higher than normal precipitable water anomalies in JAS93 (Figure 10(d)). The latter was due to anomalously strong $850 \mathrm{hPa}$ inflow in response to a stronger and equatorward displaced $200 \mathrm{hPa}$ wind maximum and a southward displaced cyclone track.

Finally, it is interesting to assess the role of ENSO in producing the anomalous cyclone tracks in the 1988 drought and 1993 flood. In JAS88, La Niña had developed, while weak El Niño was occurring in JAS93. As was discussed in Section 1, the literature shows mixed results on the role of ENSO in these events. A correlation of cyclone frequency and the EIS index is shown in Figure 11. Statistically significant negative correlations over the northern plains/southern Canada suggest that drier conditions in our area of study may have some linkage to a poleward-displaced Jetstream during La Niña. This is supported by (1) significant, positive correlations across the northern US between the storm-rain index and $200 \mathrm{hPa}$ winds shown in Figure 9 and (2) significant negative correlations between the storm-rain index and storm track frequency across southwestern Canada/northern plains as shown in Figure 8(b). Putting these results together suggests that La Niña is associated with a poleward-displaced Jetstream resulting in drier (wetter) conditions in the Midwest (southwestern Canada) in JAS, in agreement with Hoerling and Kumar [14]. This is also consistent with the 1993/1988 


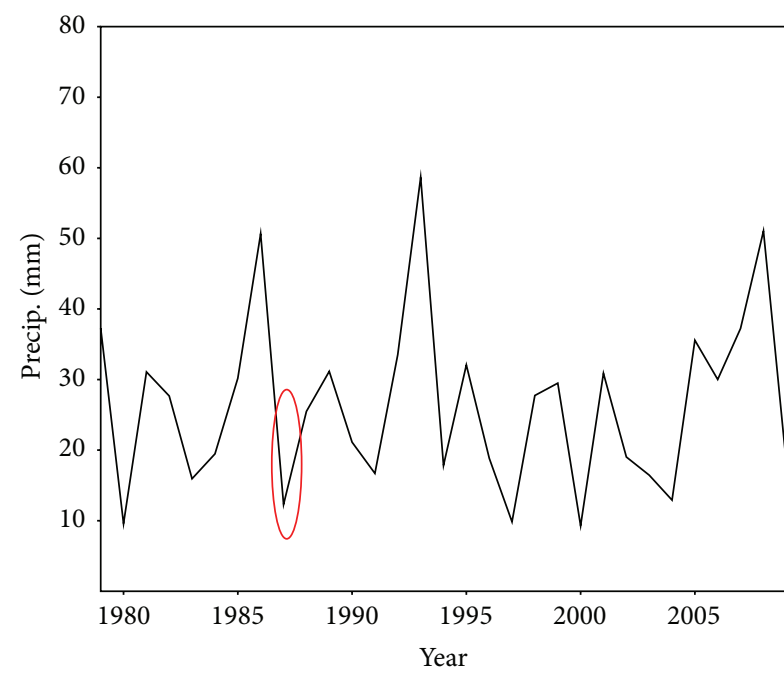

(a)

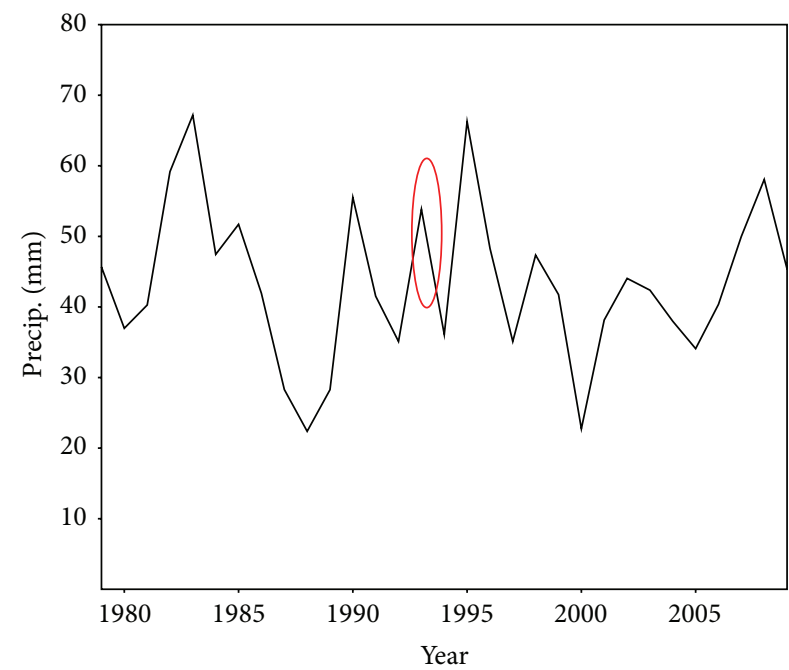

(b)

Figure 7: Storm-rainfall index for (a) AMJ, (b) JAS (units: mm). Red circles show 1988 drought and 1993 flood, respectively.
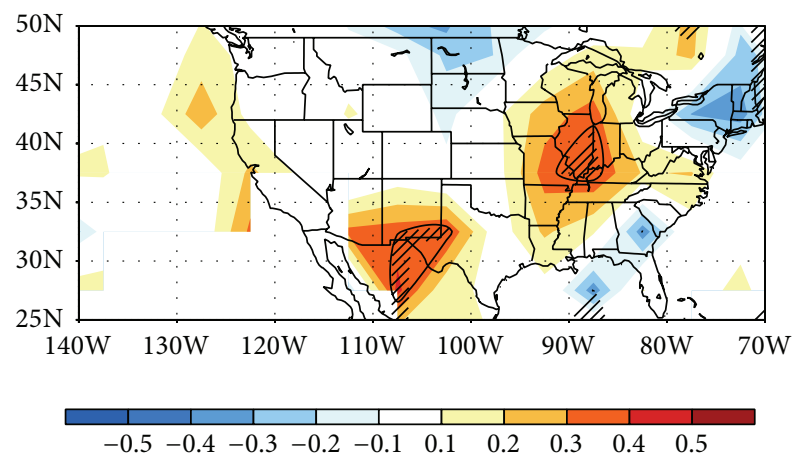

(a)

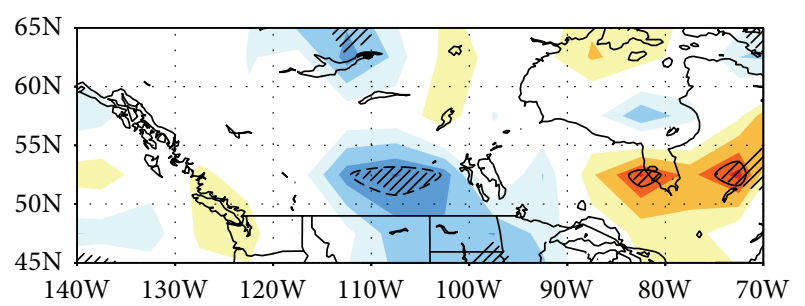

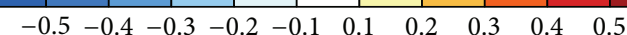

(b)

FIGURE 8: Correlation of storm-rainfall index with storm track frequency for (a) AMJ, (b) JAS. Hatched areas show 95\% significance.

storm track frequency differences in southwestern Canada (refer to Figure 4(b)).

\section{Conclusions}

Major anomalies in the North American circulation were noted in the 1988 drought and 1993 flood. The $500 \mathrm{hPa}$

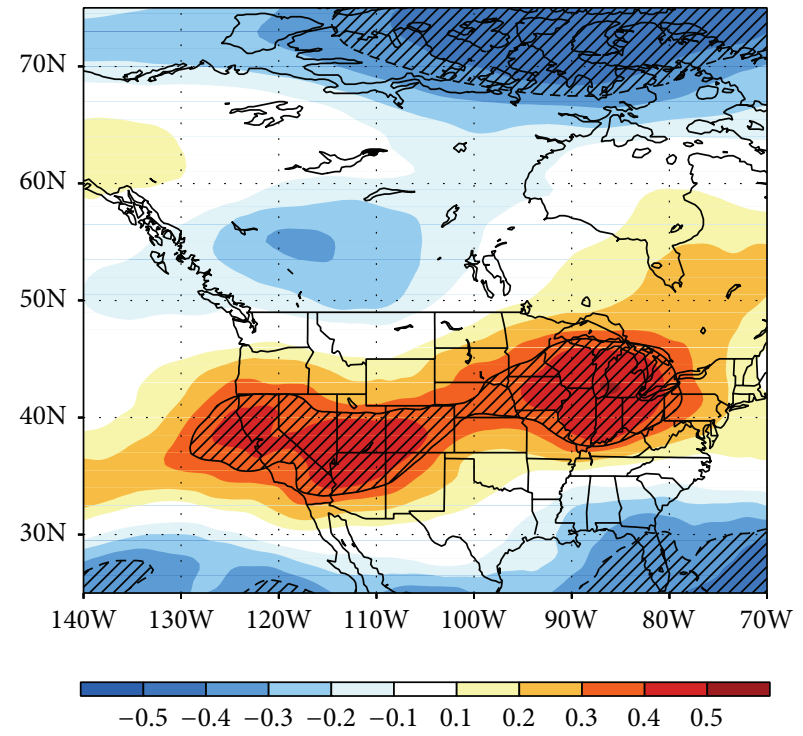

FIGURE 9: Correlation of storm-rainfall index with $200 \mathrm{hPa}$ zonal wind for JAS. Hatched areas show 95\% significance.

geopotential height pattern for the 1988 drought was notable for its persistence, with trough/ridge positions remaining fairly stationary across the North Pacific/North America from fall of 1987 to the spring of 1988. The most anomalous period was AMJ88, when an unusually strong $500 \mathrm{hPa}$ ridge was situated over the Great Plains. Associated with this ridge was (1) a northward displaced cyclone track and (2) deficits in precipitation/precipitable water. The anomalies waned during the summer of 1988, although climatologically drier conditions in the Midwest in summer relative to spring would exacerbate the dry conditions established in the spring. The poleward displacement of the $500 \mathrm{hPa}$ height pattern (especially in AMJ88) and the $200 \mathrm{hPa}$ winds (AMJ88 


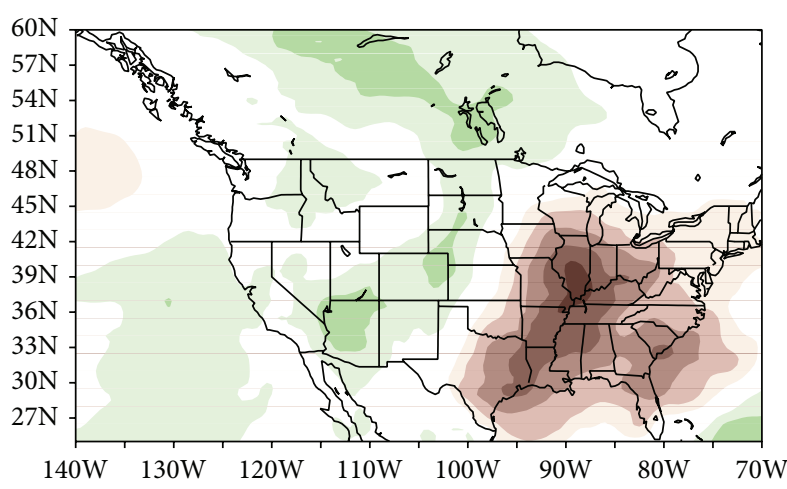

(a)

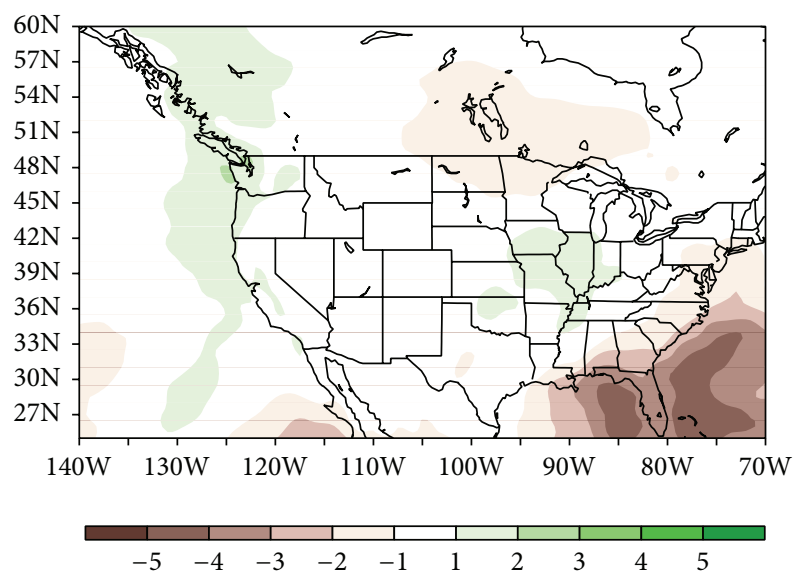

(c)

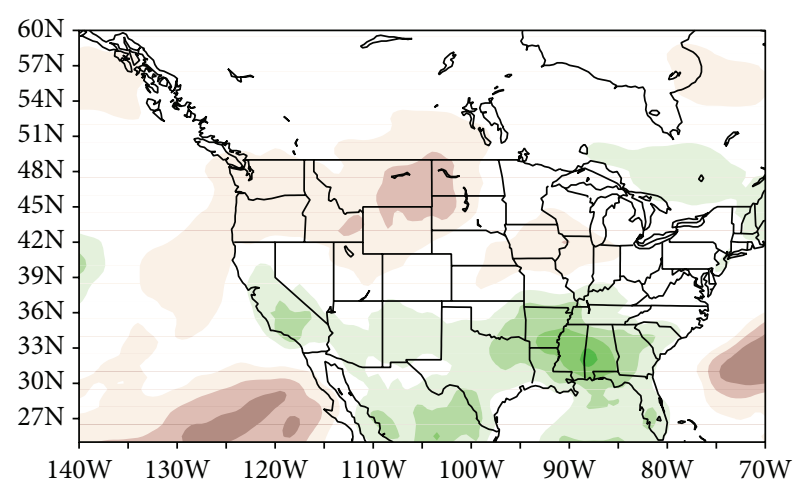

(b)

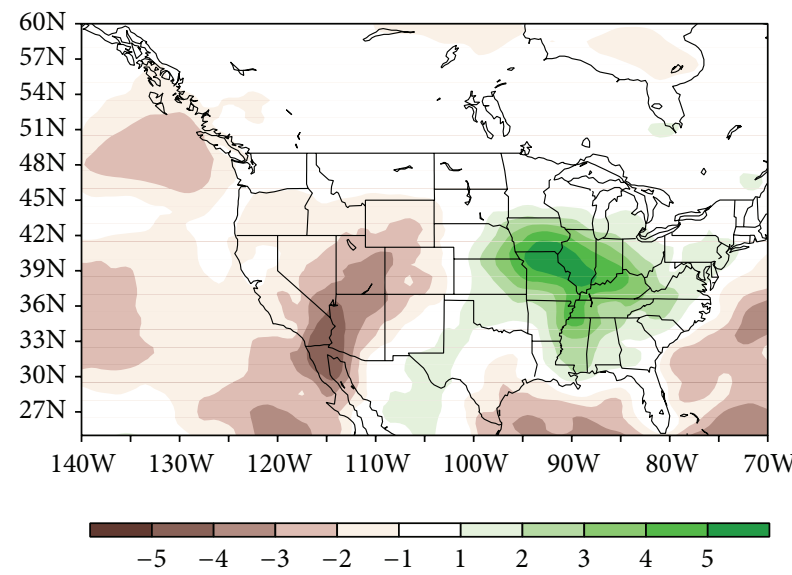

(d)

FIGURE 10: Seasonal precipitable water departures from normal (kg/mm) for (a) AMJ88, (b) JAS88, (c) AMJ93, and (d) JAS93.

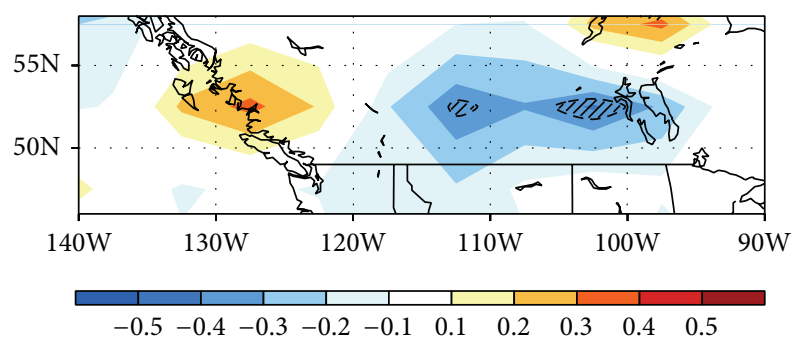

FIGURE 11: Correlation of EIS index with cyclone track frequency for JAS from 1979-2009. Hatched regions are significant at 95\%.

and JAS88) supports a poleward displacement of cyclone tracks, helping lock in the drought. The enhanced cyclone frequency across the northern plains and southern Canada in JAS88 is supported by midlevel dynamics in the form of $500 \mathrm{hPa}$ diffluence and below normal heights downstream of a stronger than normal $500 \mathrm{hPa}$ trough over the upstream Gulf of Alaska.

In contrast, the 1993 flood was marked by a more changeable $500 \mathrm{hPa}$ height pattern from the previous fall into the summer of 1993. The one persistent feature (and in opposition to 1988 ) was a region of above normal $500 \mathrm{hPa}$ heights in the Gulf of Alaska. Teleconnections the Gulf of Alaska would support a western US trough and an eastern ridge which began to evolve in AMJ93 (weak trough in southern CA) and became more amplified by JAS93. This pattern supported a southward displaced cyclone track across North America in the spring and summer of 1993. A key feature of the 1993 flood was the evolution of a strong $200 \mathrm{hPa}$ jet across the Baja/Gulf of Mexico and the upper Midwest for AMJ93 and JAS93, respectively.

Based on our analysis of storm tracks and the general circulation linked to a storm-rain index in the Midwest, the 1993 flood and 1988 drought events were linked to storm tracks as follows: (1) In AMJ93, a cyclone track with associated enhanced rainfall became established from the Gulf of Mexico to the Midwest. While this cyclone track was supported at least in part by downstream effects of a $500 \mathrm{hPa}$ trough that developed over southern Colorado, a stronger $200 \mathrm{hPa}$ jet across the subtropics from the Baja to the Gulf of Mexico also supports an increase in cyclone frequency from Mexico to the Gulf of Mexico. These cyclones tracked northeastward producing heavy rainfall across the Midwest. (2) In JAS93, a stronger than normal $200 \mathrm{hPa}$ jet across the upper Midwest contributed to the 1993 flood by (a) supporting a southward displaced cyclone track with centers across the southwestern US and eastern Canada coinciding with the right-entrance/left-exit regions, respectively, and 
(b) encouraging strong $850 \mathrm{hPa}$ inflow from the tropics (Caribbean), westward the Gulf of Mexico, and northeastward the Midwest, and (c) increasing precipitable water for the cyclones to interact with.

The roles of ENSO in contributing to the 1993 flood and 1988 drought are modest, although there is some suggestion that La Niña played a role in the 1988 drought based on a poleward-displaced cyclone track associated with a poleward-displaced $200 \mathrm{hPa}$ Jetstream. Results from our storm-rain index support the above scenario.

\section{Disclaimer}

Any opinions, findings, and conclusions or recommendations expressed in this material are those of the authors and do not necessarily reflect the views of the National Science Foundation.

\section{Conflict of Interests}

The authors declare that there is no conflict of interests.

\section{Acknowledgments}

This study is partly supported by the NOAA/MAPP Grant NA11OAR4310094. This study is partly supported by the National Science Foundation under Award no. IIA-1355406.

\section{References}

[1] NOAA, Billion-Dollar Weather/Climate Disasters, 2014, http:// www.ncdc.noaa.gov/billions/events.

[2] S. A. Changnon, "The 1988 drought, barges, and diversion," Bulletin of the American Meteorological Society, vol. 70, no. 9, pp. 1092-1104, 1989.

[3] K. Wahl, K. C. Vining, and G. J. Wiche, "Precipitation in the Upper Mississippi River Basin January 1 through July 31 1993," US Geological Survey Circular 1120-B, 1993.

[4] R. Atlas, N. Wolfson, and J. Terry, "The effect of SST and soil moisture on GLA model simulations of the 1988 U.S. summer drought," Journal of Climate, vol. 6, no. 11, pp. 2034-2048, 1993.

[5] P. Chen and M. Newman, "Rossby wave propagation and the rapid development of upper-level anomalous anticyclones during the 1988 U.S. drought," Journal of Climate, vol. 11, no. 10, pp. 2491-2504, 1998.

[6] A. Z. Liu, M. Ting, and H. Wang, "Maintenance of circulation anomalies during the 1988 drought and 1993 floods over the United States," Journal of the Atmospheric Sciences, vol. 55, no. 17, pp. 2810-2832, 1998.

[7] K. E. Kunkel, S. A. Changnon, and J. R. Angel, "Climatic aspects of the 1993 Upper Mississippi River Basin flood," Bulletin of the American Meteorological Society, vol. 75, no. 5, pp. 811-822, 1994.

[8] G. D. Bell and J. E. Janowiak, "Atmospheric circulation associated with the Midwest floods of 1993," Bulletin of the American Meteorological Society, vol. 76, no. 5, pp. 681-695, 1995.

[9] K. E. Trenberth and C. J. Guillemot, "Physical processes involved in the 1988 drought and 1993 floods in north America," Journal of Climate, vol. 9, no. 6, pp. 1288-1298, 1996.

[10] S. J. Weaver, A. Ruiz-Barradas, and S. Nigam, "Pentad evolution of the 1988 drought and 1993 flood over the great plains: an
NARR perspective on the atmospheric and terrestrial water balance," Journal of Climate, vol. 22, no. 20, pp. 5366-5384, 2009.

[11] J. Namias, "Spring and summer 1988 drought over the contiguous united states-causes and prediction," Journal of Climate, vol. 4, no. 1, pp. 54-65, 1991.

[12] K. E. Trenberth and G. W. Branstator, "Issues in establishing causes of the 1988 drought over North America," Journal of Climate, vol. 5, no. 2, pp. 159-172, 1992.

[13] R. Seager and M. Hoerling, "Atmosphere and ocean origins of North American droughts," Journal of Climate, vol. 27, no. 12, pp. 4581-4606, 2014.

[14] M. Hoerling and A. Kumar, "The perfect ocean for drought," Science, vol. 299, no. 5607, pp. 691-694, 2003.

[15] Z. Pan, M. Segal, R. Turner, and E. Takle, "Model simulation of impacts of transient surface wetness on summer rainfall in the United States Midwest during drought and flood years," Monthly Weather Review, vol. 123, no. 5, pp. 1575-1581, 1995.

[16] Z. Pan, R. W. Arritt, M. Segal, T.-C. Chen, and S.-P. Weng, "Effects of quasi-stationary large-scale anomalies on some mesoscale features associated with the 1993 flood: a regional model simulation," Journal of Geophysical Research D: Atmospheres, vol. 105, no. 24, pp. 29551-29564, 2000.

[17] S. Saha, S. Moorthi, H.-L. Pan et al., "The NCEP climate forecast system reanalysis," Bulletin of the American Meteorological Society, vol. 91, no. 8, pp. 1015-1057, 2010.

[18] M. C. Serreze, "Climatological aspects of cyclone development and decay in the Arctic," Atmosphere-Ocean, vol. 33, no. 1, pp. 1-23, 1995.

[19] F. Carse, R. G. Barry, and J. C. Rogers, "Icelandic low cyclone activity: climatological features, linkages with the NAO and relationships with recent changes in the Northern Hemisphere circulation," Journal of Climate, vol. 10, pp. 453-464, 1997.

[20] U. Neu, M. G. Akperov, N. Bellenbaum et al., "IMILASTa community effort to intercompare extratropical cyclone detection and tracking algorithms," Bulletin of the American Meteorological Society, vol. 94, pp. 529-547, 2013.

[21] T. Eichler and W. Higgins, "Climatology and ENSO-related variability of North American extratropical cyclone activity," Journal of Climate, vol. 19, no. 10, pp. 2076-2093, 2006.

[22] V. E. Kousky and R. W. Higgins, "An alert classification system for monitoring and assessing the ENSO cycle," Weather and Forecasting, vol. 22, no. 2, pp. 353-371, 2007. 

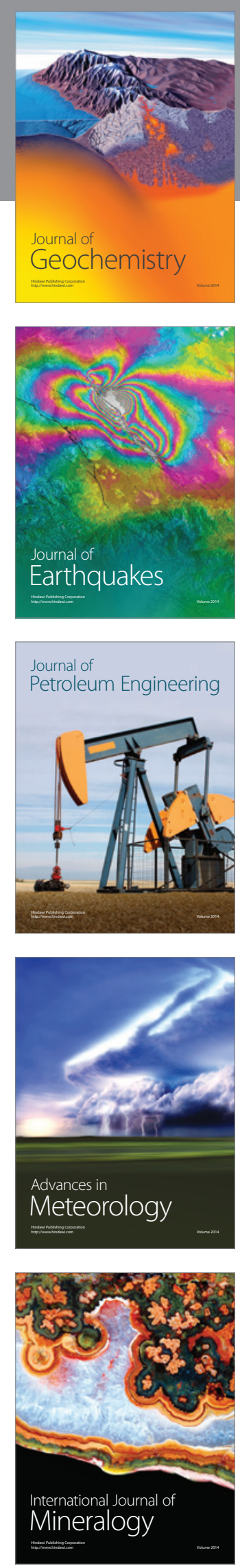
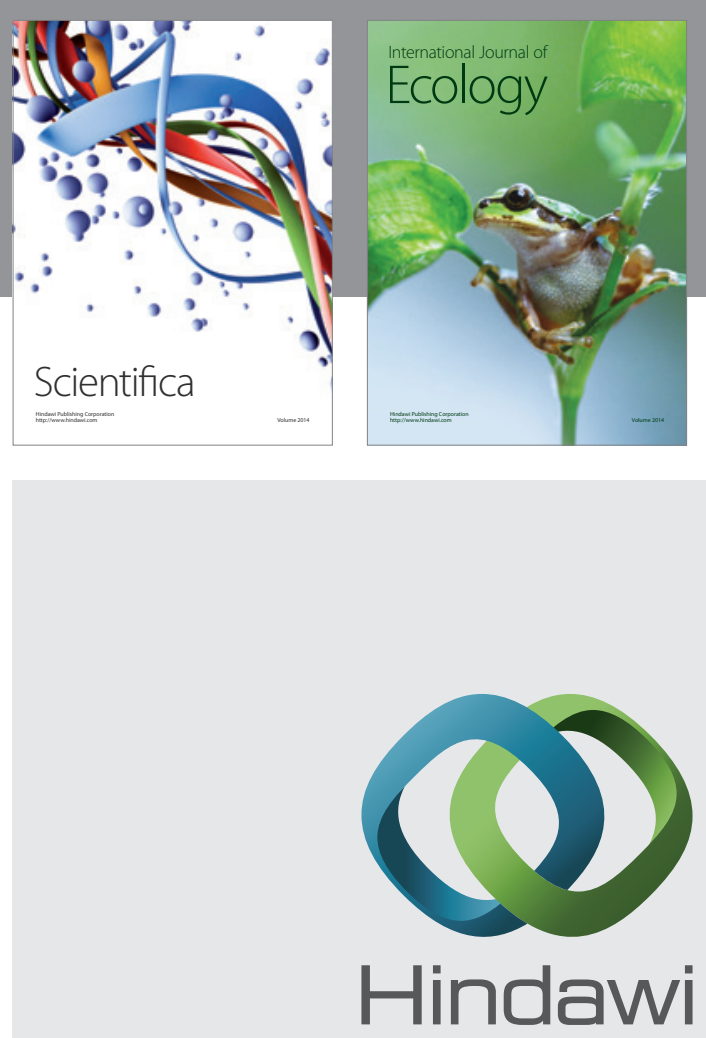

Submit your manuscripts at

http://www.hindawi.com
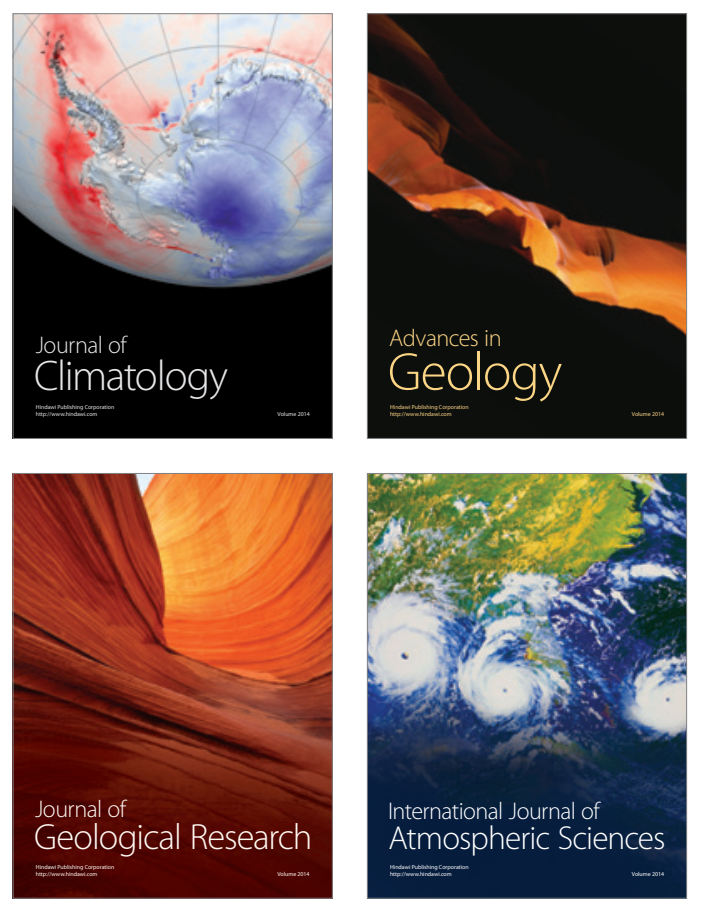

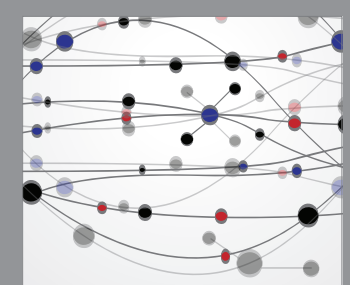

The Scientific

\section{World Journal}
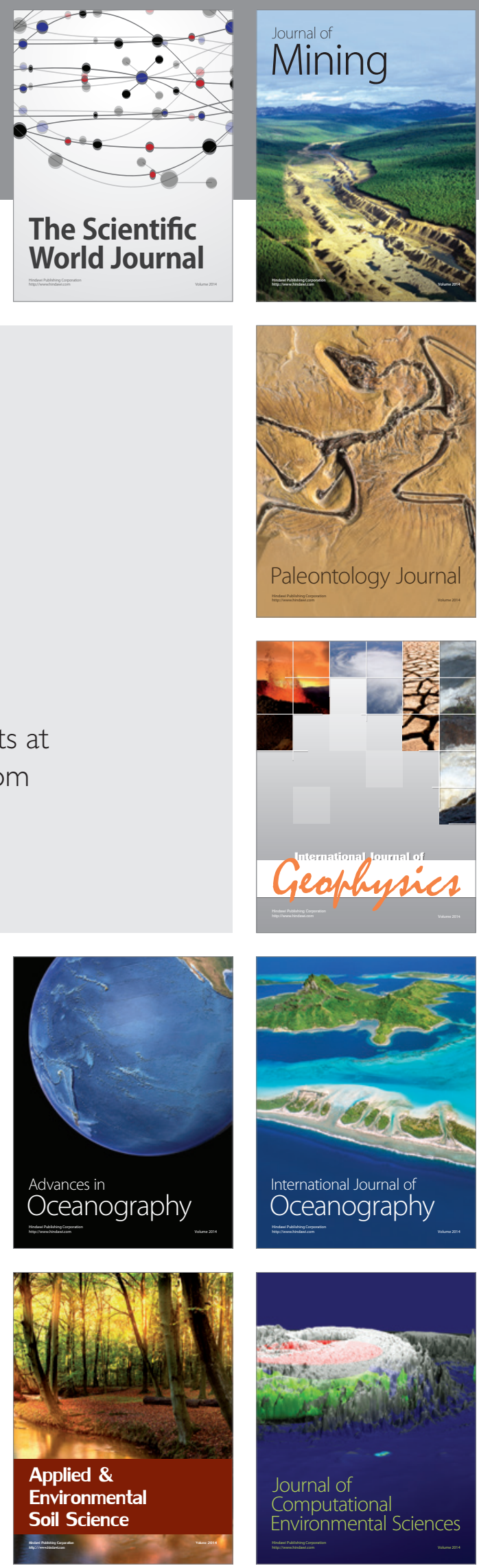